\title{
EL ALCANCE (RATIONAE MATERIAE \\ Y RATIONE PERSONAE) DEL ACUERDO DE ARBITRAJE EN DERECHO MEXICANO*
}

\author{
José Luis SIQUEIROS**
}

RESUMEN: El artículo trata sobre el alcance que tiene el Acuerdo de Arbitraje en el derecho mexicano, el cual hace referencia a la legislación mercantil y civil. La importancia de dicho acuerdo reside en su validez reconocida por tribunales mexicanos, así como por otros acuerdos internacionales. Tal acuerdo sigue los parámetros establecidos por las convenciones internacionales y la Ley Modelo de Arbitraje Comercial Internacional de la CNUDMI.

ABSTRACT: This work is about the scope of the Arbitration Agreement in Mexican Law, referring to the merchant and civil legislation, finding its relevance in the fact that the validation of this agreement has been recognized by Mexican and international tribunals. This Agreement is compatible with the parameters established in the international conventions and the Model Law of International Commercial Arbitration of the CNUDMI.

RÉSUMÉ: Cet article analyse la trascendance du Traité d'Arbitrage dans le Droit Mexicaine, en faisant reference á la legislation commerciale et civile. Sa preponderance reste dans le fait que la validation de ce traité a eté reconnue par les tribunaux Mexicaines et étrangéres. Ce Traité est compatible avec les paramètres établis dans les conventions internationales et la Loi Modèle de l'Arbitrage Commercial International du CNUDMI.

* Seminario Práctico sobre el Sistema de Arbitraje de la CCI, verificado en México, D. F., a fines de 2003 .

** Vicepresidente de la Comisión de Arbitraje, Capítulo Mexicano de la Cámara Internacional de Comercio. 
SUMARIO: I. Acuerdo de arbitraje. II. El acuerdo de arbitraje con relación a la materia del mismo (rationae materiae). III. El acuerdo de arbitraje con relación a las personas que lo celebran (ratione personae). IV. Conclusión.

\section{ACUERDO DE ARBITRAJE}

El derecho mexicano regula el acuerdo de arbitraje, tanto en el campo del derecho mercantil, como en el civil. En el ámbito comercial dicha normatividad es de carácter federal y de conformidad con el artículo 1051 del Código de Comercio, se rige por el título cuarto del libro quinto del citado ordenamiento. En el ámbito no-comercial, concretamente en el campo civil, el juicio arbitral está regulado por la legislación procesal civil del Distrito Federal ${ }^{1}$ y de cada una de las entidades federativas de la República.

La nueva legislación mercantil en materia arbitral (vigente desde 1993) está inspirada en la Ley Modelo de Arbitraje Comercial Internacional de la Comisión de las Naciones Unidas sobre Derecho Mercantil Internacional (CNUDMI) de 1985. Esta última a su vez por la Convención sobre el Reconocimiento y Ejecución de las Sentencias Arbitrales Extranjeras (Convención de Nueva York, 1958), instrumento al que se adhirió México en 1971.

El artículo 7, párrafo 1, de la Ley Modelo, establece que el "acuerdo de arbitraje" es aquél por el que las partes deciden someter a arbitraje todas o ciertas controversias que hayan surgido o puedan surgir entre ellas respecto de una determinada relación jurídica, contractual o no-contractual. El acuerdo de arbitraje podrá adoptar la forma de una cláusula compromisoria incluida en un contrato o la forma de un acuerdo independiente.

El Código de Comercio adopta la misma terminología en su artículo 1416 (I) al definir lo que es el acuerdo de arbitraje, señalando en el artículo 1423 que tal acuerdo deberá constar por escrito y consignarse en un documento firmado por las partes o en un intercambio de cartas, telex, 
telegramas, facsímil u otros medios de telecomunicación que dejen constancia del acuerdo. ${ }^{2}$

Los tribunales mexicanos, en múltiples ejecutorias, han reconocido la validez del acuerdo arbitral y concedido el reconocimiento y ejecución de los laudos que se dictan tanto en el territorio nacional, como en aquellos provenientes del extranjero.

\section{EL ACUERDO DE ARBITRAJE CON RELACIÓN A LA MATERIA DEL MISMO (RATIONAE MATERIAE)}

1. La Convención de Nueva York, en su artículo II, cuyo texto siguió casi literalmente la Ley Modelo, establece que los Estados contratantes reconocerán el acuerdo por escrito conforme al cual las partes se obliguen a someter a arbitraje todas las diferencias que hayan surgido o puedan surgir entre ellas y que sean concernientes a un asunto que pueda ser resuelto por ese mecanismo.

Sin embargo, la propia convención, en su artículo I, permite que los Estados ratificantes o adherentes puedan formular declaraciones en el sentido de que aplicarán la convención al reconocimiento y a la ejecución de sentencias arbitrales dictadas en el territorio de otro Estado contratante únicamente; asimismo, podrán declarar que sólo la aplicarán a los litigios surgidos de relaciones jurídicas, sean o no contractuales, consideradas comerciales por su derecho interno.

Por lo que respecta a la primera (posible) declaración, que México no hizo, tal omisión implica que nuestro país está internacionalmente obligado, sobre bases de reciprocidad, a reconocer y ejecutar sentencias arbitrales dictadas en el territorio de otros Estados que no sean partes del convenio neoyorkino. Si bien es cierto que este último ha sido ratificado hasta ahora por 133 naciones, teóricamente podría suscitarse el caso de un laudo arbitral emitido en un Estado no-parte que comprobara que en su territorio se reconocen y ejecutan sentencias arbitrales mexicanas.

Por lo que toca a la segunda declaración, el Estado ratificante o adherente que no la hiciese podría aplicar la convención a litigios que no fueran comerciales según su legislación doméstica. México, al adherirse al instrumento no hizo dicha declaración. En tal virtud, a partir de la ad-

2 El artículo 1423 del Código de Comercio sigue muy de cerca el párrafo 2 del artículo 7 de la Ley Modelo. 
hesión de nuestro país al instrumento multilateral, los litigios surgidos de relaciones jurídicas no-comerciales, básicamente aquellos de carácter civil, se siguieron rigiendo por su legislación interna, $i$. e. en ausencia de disposiciones específicas en el Código de Comercio se aplicaban supletoriamente los Códigos de Procedimientos Civiles de las entidades federativas y el código adjetivo del Distrito Federal. Desde luego, el arbitraje mercantil internacional comenzó a ser regulado por lo dispuesto en el convenio neoyorkino. ${ }^{3}$

2. Por otra parte, la Convención Interamericana sobre Arbitraje Comercial Internacional, suscrita en Panamá el 30 de enero de 1975 y ratificada por los Estados Unidos Mexicanos en abril de 1978, establece que "es válido el arreglo de las partes en virtud del cual se obligan a someter a decisión arbitral las diferencias que pudiesen surgir o hayan surgido entre ellas con relación a un negocio de carácter mercantil'. Queda bien claro que el instrumento no incluye diferendos de carácter civil.

3. La Ley Modelo de la CNUDMI, desde su artículo 1, inciso 1, al describir su ámbito, expresa que se aplicará al arbitraje comercial internacional. En el inciso 3 del mismo dispositivo define lo que debe entenderse por arbitraje internacional; en cambio, por lo que toca al calificativo de "comercial" sólo aparece un asterisco como nota a pie de página en el que se indica que debe darse una interpretación amplia a dicha expresión, con el fin de que abarque las cuestiones que se plantean en todas las relaciones de esa índole, contractuales o no. La misma nota prosigue indicando que las relaciones comerciales comprenden diversas operaciones, sin limitarse a ellas, ejemplificando una serie de ellas como el suministro o intercambio de bienes o servicios, de distribución, de representación o mandato comercial.

4. No fue hasta la primera reforma a nuestro código mercantil en esta materia, a fines de diciembre de 1988, cuando el arbitraje comercial a nivel nacional queda legislado por aquél. Sin embargo, dicha reforma, bienvenida por adoptar las disposiciones más importantes de la Ley Modelo de la CNUDMI, fue insuficiente. Casi cinco años después (1993), el título cuarto del libro quinto del Código de Comercio fue modificado en todo su articulado para permitir la adopción del texto completo de la citada Ley Modelo.

3 Los tratados que estén de acuerdo con la Constitución y aprobados por el Senado, serán la ley suprema de toda la unión (artículo 133 de la Constitución Política de México). 
En el mismo Diario Oficial (22-VII-1993) en el que se reforman y adicionan diversas disposiciones del ordenamiento mercantil, se publicaron también las modificaciones al Código Federal de Procedimientos Civiles (artículos 569, 570 y 571, relacionados con la ejecución de sentencias y laudos arbitrales privados), para excluir de su cobertura a aquellos que tuvieren un carácter comercial. Con las citadas reformas al código adjetivo, el legislador federal quiso explicitar que todo el ámbito del arbitraje mercantil queda fuera de los procedimientos estatales, incluyendo al Distrito Federal.

Sería necesario que el propio Congreso de la Unión, que tiene facultades para legislar en el Distrito Federal, reformara también las disposiciones del Código de Procedimientos Civiles de dicha jurisdicción en materia de cooperación procesal internacional (artículos 605 y 606), con la finalidad de excluir también a los laudos arbitrales extranjeros de carácter comercial. Sería igualmente conveniente que los congresos en todos los Estados de la república eliminaran a dichos laudos mercantiles de la normatividad local.

5. El Código de Comercio, siguiendo la pauta de la convención neoyorquina y de la Ley Modelo, establece que "acuerdo de arbitraje" es aquel por el que las partes deciden someter a este mecanismo de solución de controversias, todas o ciertas de ellas, que hayan ya surgido o puedan surgir entre ellas, respecto a una determinada relación jurídica, contractual o no-contractual. El instrumento multilateral, la Ley Modelo y el ordenamiento nacional establecen que dicho "acuerdo" podrá adoptar la forma de una cláusula compromisoria incluida en el contrato o un acuerdo independiente. Este último, normalmente conocido como "compromiso", es aquél en que las partes interesadas acuerdan cuándo surge la controversia con posterioridad a la conclusión del contrato que las vincula, o en el curso de relaciones comerciales entre ellas, que no están reguladas en forma contractual. Mediante dicho acuerdo las partes convienen en resolver su diferendo sin acudir a los órganos judiciales y en acatar el laudo que emita el árbitro o árbitros que se designen al inicio del procedimiento.

El procedimiento arbitral de carácter comercial puede ser administrado por una institución arbitral permanente, como puede ser la Corte Internacional de Arbitraje de la Cámara de Comercio Internacional (CCI), la Asociación Americana de Arbitraje (AAA), la Cámara Nacional de Comercio de la Ciudad de México (Canaco) o cualquiera otra que 
pacten las partes involucradas; puede ser también ad-hoc o no-administrado, cuando el proceso arbitral se conduce sin someterse a una institución arbitral y sólo conforme a normas que en cada caso adoptan las partes y los árbitros.

De conformidad con el código mercantil, el acuerdo arbitral deberá constar por escrito y consignarse en documento firmado por las partes o en un intercambio de cartas, telex, telegramas, facsímil u "otros medios de telecomunicación que dejen constancia del acuerdo". En los tiempos actuales en que la telecomunicación electrónica prevalece, el acuerdo puede celebrarse por correos electrónicos o a través del Internet, siempre que pueda obtenerse una constancia gráfica posterior de dicho consenso; puede también derivar de un intercambio de escritos de demanda y contestación en los que la existencia de tal acuerdo sea afirmada por una parte sin ser negada por la otra.

El juez mexicano al que se someta un litigio sobre un asunto que ha sido objeto de un acuerdo de arbitraje, remitirá a las partes a dicho procedimiento arbitral si así lo solicita cualquiera de ellas, a menos que se comprobara que el supuesto acuerdo es nulo, ineficaz o de ejecución imposible. Sin embargo, si se entabla ante el juez una acción que impugna el acuerdo como nulo o ineficaz, se podrá no obstante iniciar o proseguir las actuaciones arbitrales e incluso dictarse laudo mientras la cuestión esté pendiente ante la autoridad judicial.

6. La acción de nulidad o ineficacia del acuerdo arbitral puede fundarse en que la materia del mismo no es susceptible de ser resuelta por arbitraje de naturaleza privada; a mayor abundamiento, el laudo dictado por los árbitros en un asunto que según el derecho mexicano no es arbitrable, conducirá a la nulidad del mismo por juez competente, o a que se le deniegue el reconocimiento y la ejecución, cualquiera que sea el país en que se hubiere dictado.

Como es ya sabido, existen algunas materias que por su naturaleza misma no "pueden comprometerse en árbitros"4 según la terminología que aún conserva el CPCDF. En muchas leyes federales regulatorias de materias de interés público se establece que las diferencias que puedan surgir entre el organismo público competente para administrar tales materias y los particulares, no pueden dirimirse por arbitraje. En otros orde-

4 El artículo 615 del Código de Procedimientos Civiles para el Distrito Federal consigna una lista de los "negocios" no susceptibles de resolverse por este mecanismo. 
namientos federales se precisa que dichas diferencias se resolverán en instancias específicas de arbitraje en el que un órgano oficial actúa como participante en el proceso. Dicho en otras palabras, la controversia normalmente se resolverá ante los tribunales de la Federación, salvo que el legislador autorice en la Ley Orgánica que regula la actividad de tales entidades públicas o paraestatales que aquellas puedan ser sometidas a un acuerdo arbitral si así conviene al mejor cumplimiento de su objeto. ${ }^{5}$

\section{EL ACUERDO DE ARBITRAJE CON RELACIÓN A LAS PERSONAS QUE LO CELEBRAN (RATIONE PERSONAE)}

Como hemos visto, tanto la Convención de Nueva York (artículo II), como la Convención Interamericana sobre Arbitraje Comercial Internacional (Convención de Panamá, artículo 1), establecen con ligeras diferencias en su terminología, que "se reconocerá" o "será válido" el acuerdo por el que "las partes" se obliguen a someter al arbitraje las diferencias que pudiesen surgir o que hayan surgido entre ellas respecto a "una determinada relación jurídica, contractual o no-contractual, concerniente a un asunto que pueda ser resuelto por ese método" (Convención de Nueva York), o "con relación a un asunto de carácter mercantil" (Convención de Panamá).

Es interesante advertir que ni en el instrumento adoptado por la Organización de las Naciones Unidas ni en el auspiciado por la Organización de los Estados Americanos se define quienes pueden ser "las partes" en el acuerdo. La primera convención quedó abierta a todos los Estados miembros de la ONU y de cualquier otro Estado que sea o llegue a ser miembro de sus organismos especializados parte en el Estatuto de la Corte Internacional de Justicia, o a ser invitado por la Asamblea General. En la segunda convención se dice que la misma estará abierta a la firma de los Estados miembros de la OEA, sin perjuicio de la adhesión de cualquier otro Estado.

La Comisión de Asesores Externos de la Secretaría de Relaciones Exteriores realizó en 1987 y 1988 un estudio para adicionar el Código de Comercio con un nuevo título cuarto (a su libro quinto "De los Juicios Mercantiles"), titulado "Del Arbitraje Comercial". La citada comisión

5 Véase artículo 14 de la Ley Orgánica de Petróleos Mexicanos y Organismos Subsidiarios, y artículo 45 de la Ley del Servicio Público de Energía Eléctrica. 
preparó un proyecto inspirado en la Ley Modelo que incorporaba a nuestro derecho positivo los principios básicos de las convenciones de Nueva York y Panamá. La iniciativa de reformas no lo materializó. El Congreso de la Unión aprobó en diciembre de 1988 un decreto ${ }^{6}$ por el que se reforman, adicionan y derogan diversas disposiciones del Código de Comercio. De este conjunto de normas sólo seis corresponden al articulado de la Ley Modelo; los otros diecisiete dispositivos incorporaban preceptos contenidos en el Código de Procedimientos Civiles del Distrito Federal y de otros ordenamientos procesales estatales. Para los efectos de este trabajo, sólo nos referiremos al artículo 1415 (el primero del título cuarto) que establecía que "cuando las partes sean comerciantes podrán convenir en someter a decisión arbitral las diferencias que surjan de sus relaciones comerciales". El artículo 1416 dejaba constancia de que sólo las personas capaces pueden comprometer en árbitros sus negocios.

Estas reformas al ordenamiento mercantil sólo estuvieron vigentes cuatro años y medio, pero debe enfatizarse que su articulado precisó que las partes deberían ser: a) Comerciantes y b) Personas capaces. Si bien ambas cualidades pueden considerarse como obvias en un código mercantil, se destacan porque en la nueva legislación que entró en vigor en julio de 1993 no se hace ninguna alusión a ellas. El nuevo título cuarto establece que las disposiciones del mismo "se aplicarán al arbitraje comercial nacional, y al internacional cuando el lugar del arbitraje se encuentre en territorio nacional, salvo lo dispuesto en los tratados internacionales de que México sea parte o en otras leyes que establezcan un procedimiento distinto o que dispongan que determinadas controversias no sean susceptibles de arbitraje".

Las disposiciones vigentes no hacen ninguna definición de "las partes" en su artículo 1416; no obstante, debemos interpretar su contenido y entender que están referidas a negocios o asuntos en que aquellas (las partes) actúan o se reputan en derecho como "comerciantes". ¿Quienes? Aquellos a que se refiere el artículo 3o. del mismo código: a) Personas (físicas) que teniendo capacidad real para ejercer el comercio, hacen de él su ocupación ordinaria; b) Las sociedades (personas morales) constituidas de conformidad a las leyes mercantiles, y c) Las sociedades extranjeras, o las agencias y sucursales de éstas que ejerzan en el país actos mercantiles. Las personas que accidentalmente o sin establecimiento fijo, 
hagan alguna operación de comercio, aunque no sean en derecho comerciantes, quedan sujetas a las leyes mercantiles. ${ }^{7}$

Queda sólo precisar, sin embargo, si dentro de la antes citada legislación quedan también comprendidas las personas morales de derecho público, tales como el Estado federal mismo, los Estados de la Federación, sus municipios, los organismos públicos estatales o paraestatales. Es decir, si dichas entidades públicas pueden ventilar sus controversias cuando sean parte en procesos arbitrales. Tal posibilidad existe cuando actúan en su capacidad iure gestionis, es decir, como sujetos de derecho privado, y no como entes iure imperii con potestad de autoridad pública.

En el mundo actual, y México no es la excepción, la participación del Estado o de sus organismos descentralizados en la actividad económica, dentro y fuera del país, es un hecho innegable. Es palpable el deseo del sector público para favorecer la apertura comercial y de participar en la negociación contractual con la iniciativa privada. Las reformas a la Ley Orgánica de Petróleos Mexicanos y a la Ley del Servicio Público de Energía Eléctrica, ${ }^{8}$ así lo comprueban. La aceptación del legislador mexicano para armonizar dicha apertura comercial - a través de la celebración de múltiples tratados de libre comercio - con la factibilidad de celebrar acuerdos arbitrales a nivel nacional e internacional que permitan resolver eventuales controversias fuera de la jurisdicción de los tribunales judiciales, es una tendencia positiva.

\section{CONCLUSIÓN}

En resumen, podemos concluir que el alcance del acuerdo arbitral en derecho mexicano, tanto en relación con la materia involucrada, como las partes que lo celebran, está acorde con los parámetros establecidos en las convenciones universales y regionales, así como en la Ley Modelo de Arbitraje Comercial Internacional de la CNUDMI. 